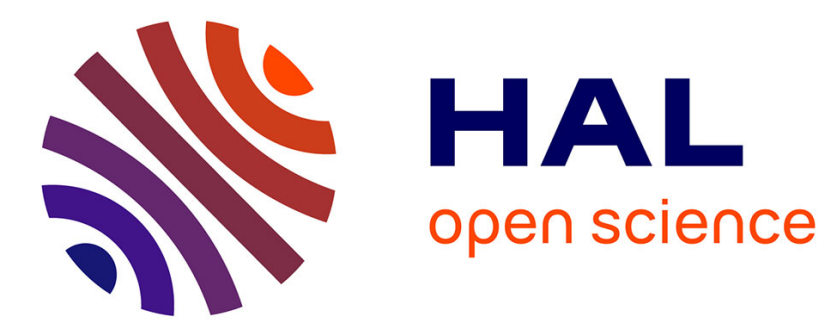

\title{
A cyanide and hydroxo-bridged nanocage: a new generation of coordination clusters
}

Abhishake Mondal, Sonja Durdevic, Lise-Marie Chamoreau, Yves Journaux, Miguel Julve, Laurent Lisnard, Rodrigue Lescouëzec

\section{- To cite this version:}

Abhishake Mondal, Sonja Durdevic, Lise-Marie Chamoreau, Yves Journaux, Miguel Julve, et al.. A cyanide and hydroxo-bridged nanocage: a new generation of coordination clusters. Chemical Communications, 2013, 49 (12), pp.1181. 10.1039/c2cc38404c . hal-02326599

\section{HAL Id: hal-02326599 \\ https://hal.science/hal-02326599}

Submitted on 23 Oct 2019

HAL is a multi-disciplinary open access archive for the deposit and dissemination of scientific research documents, whether they are published or not. The documents may come from teaching and research institutions in France or abroad, or from public or private research centers.
L'archive ouverte pluridisciplinaire HAL, est destinée au dépôt et à la diffusion de documents scientifiques de niveau recherche, publiés ou non, émanant des établissements d'enseignement et de recherche français ou étrangers, des laboratoires publics ou privés. 


\title{
Cyanide and hydroxo-bridged nanocage: a new generation of magnetic coordination clusters ${ }^{\ddagger}$
}

\author{
Abhishake Mondal, ${ }^{a}$ Sonja Durdevik, ${ }^{a}$ Lise-Marie Chamoreau, ${ }^{a}$ Yves Journaux, ${ }^{a}$ Miguel \\ Julve, ${ }^{b}$ Laurent Lisnard, ${ }^{a, *}$ and Rodrigue Lescouëzec ${ }^{a, *}$
}

\begin{abstract}
Marrying serendipitously-formed hydroxo clusters, $\left[\mathrm{Co}_{3}{ }_{3}(\mathrm{OH})(\text { piv })_{4}(\mathrm{~L})\right]^{+}$(where $\mathrm{L}=\mathrm{MeCN}$ or Hpiv), with self-assembly-driving cyanide building blocks, $\left[\mathrm{Fe}^{\prime \prime \prime}(\mathrm{Tp})(\mathrm{CN})_{3}\right]^{\text {, }}$, has led to an unprecedented architecture where polymetallic cobalt clusters and blocked tris-cyanide iron complexes define the apexes of a unique magnetic cubic nanocage.
\end{abstract}

The study of Molecule-based Magnetic Materials (MMMs) is an emerging area of material sciences devoted to the design of sophisticated molecular systems exhibiting original physical properties. For instance, the study of Single Molecule Magnets (SMMs) and switchable magnetic materials have become outstanding topics of that research field which offer promising perspectives for high-density data storage and molecular electronics. ${ }^{1}$ Two conceptually divergent synthetic strategies are dominantly used for the synthesis of MMMs: serendipitous self-assembly and designed assembly. ${ }^{2}$ The former lies on the use of sensibly chosen ligands that can display multi-binding modes through distinct coordination sites and thus promote magnetic exchange between several metal ions, with no assumptions on the final products' shapes or nuclearities, when the latter consists in the preparation and use of specific building blocks that will controllably selfassemble to form predictable architectures with targeted magnetic properties. The oxo/hydroxo and cyanide groups, which are among the most popular bridging ligands for the design of MMMs, provide archetypal examples of each synthetic approach.

The complex $\left[\mathrm{Mn}_{12} \mathrm{O}_{12}\left(\mathrm{CH}_{3} \mathrm{COO}\right)_{16}\left(\mathrm{H}_{2} \mathrm{O}\right)_{4}\right]^{3}$ is one of the most studied $\mathrm{SMM}^{4}$ and represents an emblematic example of the serendipity approach and its efficiency in preparing SMMs. ${ }^{5}$ This can be related with: (i) the remarkable ability of the oxo/hydroxo bridge in transmitting the exchange interaction, J, (ii) the easy access to polymetallic species through the control of the condensation process. However control over the exchange interaction or the magnetic anisotropy is difficult and access to heterometallic complexes and ferrimagnetic behaviours is not trivial. The programmed self-assembly of preformed building blocks offers a straightforward alternative route for the synthesis of (heterometallic) materials with predictable architectures and properties. This method has been widely used for the preparation of cyanide based MMMs. Indeed the cyanide chemistry gives access to a great number of (stable) building blocks whose electronic properties and topology can be tuned almost at will. ${ }^{6}$ Outstanding examples of cyanide-based MMMs include Prussian blue analogues (PBAs) with high Curie temperature, photomagnetic molecular materials, and molecular nano-magnets: Single Chain Magnets (SCM) and SMMs. ${ }^{7}$

In this communication we report a new synthetic strategy that combines programmed self-assembly with serendipitous clustering. It provided us with the first cyanide- and hydroxo-bridged coordination cluster:

$\left\{\left[\mathrm{Co} "(\mathrm{MeCN})_{6}\right] \subset\left[\mathrm{Fe}_{2}{ }_{2} \mathrm{Fe}^{\prime \prime \prime}{ }_{2}(\mathrm{Tp})_{4}(\mathrm{CN})_{12} \mathrm{Co}_{12}{ }_{12}(\mathrm{OH})_{4}(\text { piv })_{16}(\mathrm{Hpiv})_{4}(\mathrm{MeCN})\right]\right\} 8.5 \mathrm{MeCN} \cdot 2.5 \mathrm{H}_{2} \mathrm{O}, 1$ (Tp = tris(pyrazolyl)borate; Hpiv = pivalic acid). The synthetic route we have elaborated consists in reacting stable cyanide-based assembling complexes together with preformed anisotropic coordination clusters, which are flexible building-blocks that can rearrange in situ to link the cyanide complexes. The cluster we have chosen is the dinuclear neutral complex: $\left[\mathrm{Co}_{2}\left(\mathrm{OH}_{2}\right)(\text { piv })_{4}(\mathrm{Hpiv})_{4}\right]_{., 9}$ It displays a high versatility: alone it recombines in solution yielding homo- and hetero-valent species with nuclearities ranging from three to fourteen cobalt ions ${ }^{8}$ and used as a reactant it can lead to remarkable nanosized cages. ${ }^{10}$ The dinuclear cluster is also a known starting material for SMM preparation. ${ }^{11}$ More generally the magnetic anisotropy inherent to cobalt(II) ions have, over the past few years, attracted considerable interest and motivated tremendous work on the synthesis of cobalt-based coordination clusters. ${ }^{12}$ The cyanide-bearing building block that we have selected is the low-spin iron(III) anionic complex of formula $\left[\mathrm{Fe}(\mathrm{Tp})(\mathrm{CN})_{3}\right]{ }^{-13}$. This complex belongs to the family of "substituted cyanometallates" of general formula $\left[M(L)(C N)_{x}\right]^{n-}$, which have been specifically designed for the synthesis of low-dimensional materials. ${ }^{14}$ In contrast with the hexacyanometallates, the use of partially blocked cyanide building blocks restrains the possibilities of polymerization (Scheme 1). ${ }^{15}$ The $\left[\mathrm{Fe}(\mathrm{Tp})(\mathrm{CN})_{3}\right]$ - building block exhibits a stable topology, the three cyanide groups located in fac positions favour the occurrence of $\left\{\mathrm{M}-\mathrm{CN}-\mathrm{M}^{\prime}\right\}$ fragments orthogonal to each other. As a consequence, its use often leads to polynuclear systems containing $\left\{\mathrm{Fe}_{2} \mathrm{M}_{2}\right\}$ square motifs. ${ }^{14}$ The fac topology is also very well suited for the design of cubic complexes and several $\left\{\mathrm{Fe}_{4} \mathrm{M}_{4}\right\}$ molecular models of the PBAs have been rationally designed by reacting fac$\left[\mathrm{Fe}(\mathrm{L})(\mathrm{CN})_{3}\right]^{-}$complexes with partially blocked fac- $\left[\mathrm{M}\left(\mathrm{L}^{\prime}\right)(\mathrm{S})_{3}\right]^{\mathrm{n}+}$ cationic units $\left(\mathrm{L}\right.$, $\mathrm{L}^{\prime}$ : tridentate blocking ligand; $\mathrm{S}$ : labile 
solvent molecules). ${ }^{16}$ For example, S. Holmes et al. reported in 2008 a cubic $\left\{\mathrm{Fe}_{4} \mathrm{Co}_{4}\right\}$ cage exhibiting interesting thermallyand photo-induced electron transfer properties. ${ }^{16 a}$ Actually, such discrete cyanide-bridged $\{$ Fe-Co\} systems are currently attracting a strong interest because of their photo-switchable magnetic properties. It is also worth noticing that these complexes may exhibit SMM-like behaviour in the photo-induced paramagnetic state, as illustrated by the very recent works from O. Sato et al. and H. Oshio et al. ${ }^{17}$

(a)
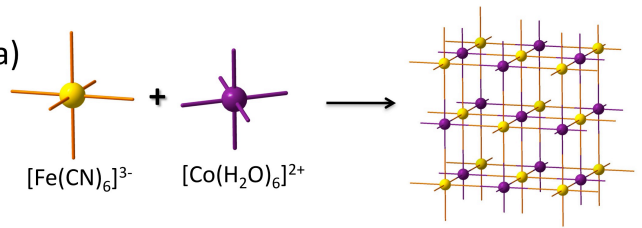

(b)

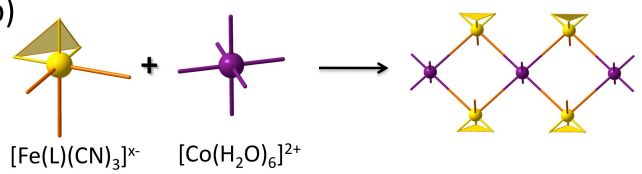

(c)

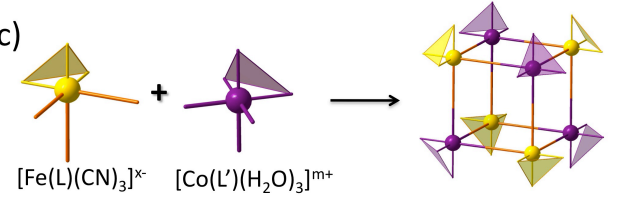

(d)

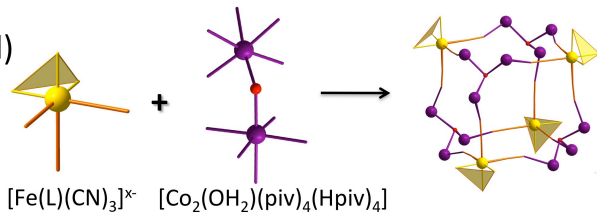

Scheme 1. Different synthetic strategies based on the self-assembly of cyanide building blocks leading to Fe-Co MMMs: (a) three dimensional (3D) structure of photomagnetic PBAs; (b) one-dimensional (1D) structure of SCMs; (c) Discrete cubic model (OD) complex of photomagnetic PBAs; (d) new approach for designing hydroxo/oxo-cyanide mixed systems.

The reaction of the $\left[\mathrm{Co}_{2}\left(\mathrm{OH}_{2}\right)(\text { piv })_{4}(\mathrm{Hpiv})_{4}\right]$ and $\left[\mathrm{Fe}(\mathrm{Tp})(\mathrm{CN})_{3}\right]^{-}$building blocks in acetonitrile yielded prismatic red crystals of complex 1 by slow evaporation. The crystal structure of 1 is made of an anionic $\left\{\mathrm{Fe}_{4} \mathrm{Co}_{12}\right\}^{2-}$ cubic nanocage cryptating a $\left[\mathrm{Co}^{\prime \prime}\left(\mathrm{CH}_{3} \mathrm{CN}\right)_{6}\right]^{2+}$ complex, and crystallisation molecules (Figure 1).

The corners of the cube are alternatively occupied by fac-[Fe" $\left.{ }^{\| / \prime \prime}(\mathrm{Tp})(\mathrm{CN})_{3}\right]^{-/ 2-}$ complexes and $\left[\mathrm{Co}_{3}{ }_{3}(\mathrm{OH})(\text { piv })_{4}(\mathrm{~L})\right]^{+}$(where $\mathrm{L}=$ $\mathrm{MeCN}$ or Hpiv) trimetallic clusters whereas the edges are defined by the $\mathrm{Fe}-\mathrm{CN}-\mathrm{Co}$ bonds, all cyanide acting as bridging ligands. Each cobalt cluster has a $\mu_{3}-\mathrm{OH}$ capping group that lies below the metallic plane and $\mu: \eta_{1}: \eta_{1}$ bridging pivalate groups are found along the edges of the triangle defined by the cobalt atoms (See SI). Structural differences between the tricobalt units arise from the $\mu_{1} \eta_{1}: \eta_{1}$ or $\mu_{3}: \eta_{2}: \eta_{1}$ coordination modes observed for the fourth bridging pivalate group in each cluster as well as the presence of pivalic acid or acetonitrile as terminal ligand (see SI for more details). As a result, six-, fiveand four-coordinate cobalt(II) ions are found in the polymetallic cage. The observed $\mathrm{Fe}-\mathrm{C}$ and $\mathrm{Fe}-\mathrm{N}$ bond distances indicate the presence of two reduced iron(II) ions which is consistent with BVS calculations and charge balancing that support the presence of thirteen cobalt(II) ions, four hydroxide anions and three non-deprotonated pivalic acid (See SI). The acetonitrile molecules in the encapsulated $\left[\mathrm{Co}^{\prime \prime}\left(\mathrm{CH}_{3} \mathrm{CNN}\right)_{6}\right]^{2+}$ complex points toward the six faces of the cube. Within the cube the $\{\mathrm{Fe}-\mathrm{C}-\mathrm{N}-\mathrm{Co}\}$ edges are slightly bent with average angles close to linearity for $\{\mathrm{Fe}-\mathrm{C}-\mathrm{N}\}$ (175.8 $8^{\circ}$ [173.6-176.9]) but smaller for $\{\mathrm{C}-\mathrm{N}-\mathrm{Co}\}\left(163.2^{\circ}[153.8-167.9]\right)$. The values of the Fe-Co distances along the edges range from 4.98 to $5.09 \AA$ with a mean value of $5.03 \AA$ and the shortest intermolecular metal-metal distance found is of $10.16 \AA$, which actually compares to the longest intracube metal-metal distances (from 11.08 to $11.99 \AA$ ). In comparison to the largest $\left\{\mathrm{Fe}(\mathrm{Tp})(\mathrm{CN})_{3}\right\}$-based heteropolycyanometalates, 1 represents a fine example of nanocage with sixteen metal centres and it sets the highest nuclearity observed so far. ${ }^{18}$ 


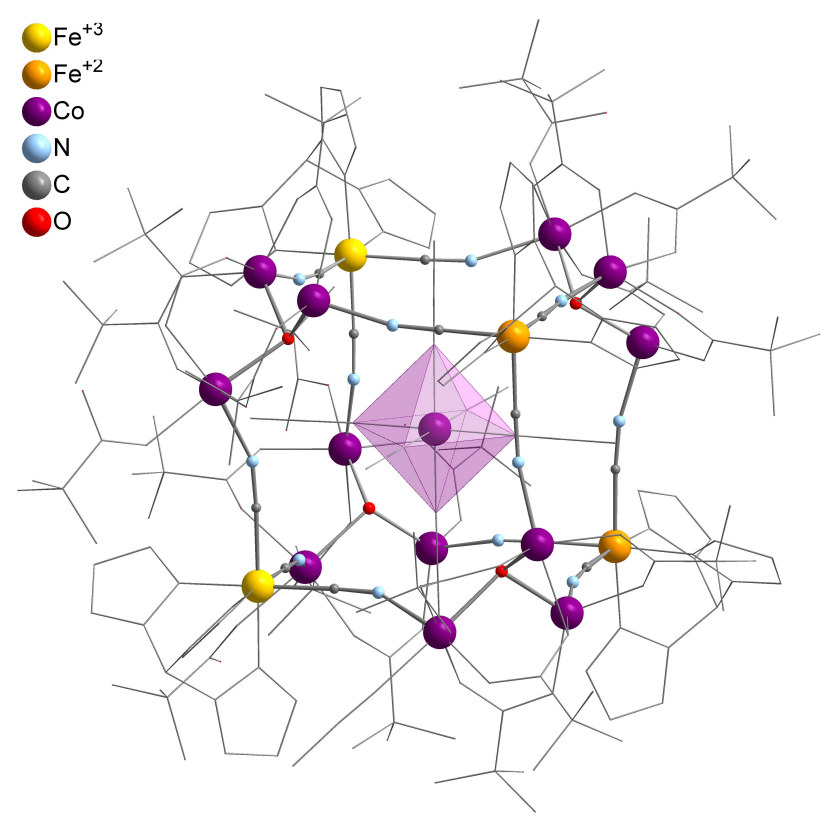

Figure 1. Structure of 1 and its hydroxo- and cyanide-bridged core. The free solvent molecules were omitted for clarity.

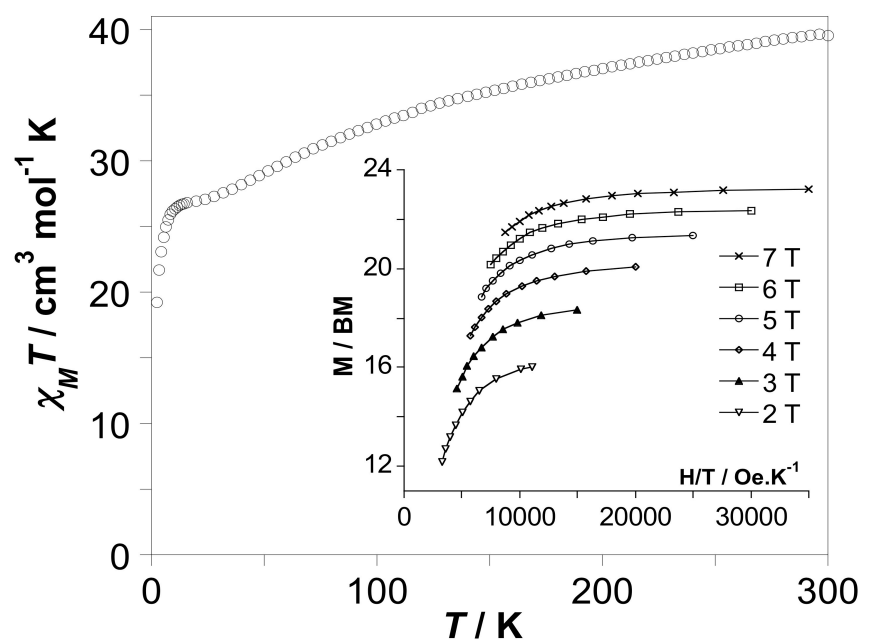

Figure 2. $\chi_{M} T$ vs. $T$ plot for 1 (solid line is the best fit curve, see text). Insert: $M$ vs. $H / T$ curve for 1 in the $2-7 \mathrm{~T}$ magnetic field range and between 1.8 and $8 \mathrm{~K}$ (solid lines are eye guides).

The magnetic properties of 1 have been investigated measuring the thermal dependence of the $\chi_{M} T$ product $\left(\chi_{M}\right.$ being the magnetic molar susceptibility per $\left\{\mathrm{Fe}_{4} \mathrm{CO}_{13}\right\}$ unit) in the $2-300 \mathrm{~K}$ temperature range at $2.5 \mathrm{kOe}$ (Figure 2). The $\chi_{M} T$ value at $300 \mathrm{~K}, 39.6 \mathrm{~cm}^{-1} \mathrm{~mol}^{-1} \mathrm{~K}$, lies within the expected range for the following set of non-interacting ions: (i) two low-spin Fe(II) $(\mathrm{S}=0)$, (ii) two low- spin Fe(III) ions $\left(\mathrm{S}=1 / 2 ; \chi_{M} T \sim 0.7 \mathrm{~cm}^{3} \mathrm{~mol}^{-1} \mathrm{~K} \text { per ion, with } \mathrm{g}=2.6\right)^{19}$ and (iii) thirteen high-spin Co(II) ions $\left(\mathrm{S}=3 / 2 ; 2.7<\chi_{\mathrm{M}} \mathrm{T}<3.4 \mathrm{~cm}^{3} \mathrm{~mol}^{-1} \mathrm{~K}\right.$ per ion), ${ }^{20}$ with paramagnetic ions exhibiting a significant orbital contribution to their magnetic moment. On lowering the temperature, the $\chi_{M} T$ value first smoothly decreases, reaching a plateau between 20 and $10 \mathrm{~K},\left(\chi_{M} T=26.7 \mathrm{~cm}^{3} \mathrm{~mol}^{-1} \mathrm{~K}\right)$ and finally decreases more abruptly down to $2.0 \mathrm{~K}\left(\chi_{M} T=17.7 \mathrm{~cm}^{3} \mathrm{~mol}^{-1} \mathrm{~K}\right)$. The decrease of $\chi_{M} T$ from room temperature to $50 \mathrm{~K}$ can be ascribed to the effect of spin-orbit coupling (Co(II) and Fe(III) ions exhibiting ${ }^{4} T_{1 g}$ and ${ }^{2} T_{2 g}$ ground terms, respectively). Indeed, a good fit is obtained with a model taking into account $13 \mathrm{Co}(\mathrm{II})$ and 2 $\mathrm{Fe}(\mathrm{III})$ ions, spin-orbit interaction and no exchange interaction between ions. ${ }^{20,}$ The plateau around $20 \mathrm{~K}$ could be the signature of the weak ferromagnetic interaction between the low-spin iron(III) and cobalt(II) ions. ${ }^{14}$ Finally, the sharp decrease at low temperature may be assigned to anisotropy effects. Indeed the isofield lines are not superposable in the reduced magnetisation versus $H / T$ plot (insert, Figure 2), which usually, comes from a significant magnetic anisotropy (see $\mathrm{SI}$ ). Nonetheless, no out-of-phase AC magnetic susceptibility signal was observed down to 2 K, discarding so the occurrence of slow magnetic relaxation. Beside, 1 does not show any photomagnetic effect under laser light irradiation in 
the visible range. Overall, the thorough analysis and the simulation of the magnetic data are precluded because of the size of the system.\&

\section{Conclusions}

We have started a promising synthetic approach, which gives access to a new generation of cluster-based molecular magnets where are married, for the first time, two popular ligands traditionally used separately in molecular magnetism: the oxo/hydroxo and cyanide bridges. In the present example, the use of a versatile oxo-based cluster toward a partially blocked cyanide building block has led to an unprecedented hydroxo-cyanide based supramolecular cubic nanocage. Beyond its use in molecular magnetism, the novel synthetic approach that we have developed is also relevant for the molecular chemists interested in the design of discrete polymetallic systems.

\section{Notes and references}

a Institut Parisien de Chimie Moléculaire, UMR 7201, UPMC, Univ Paris 06, Paris, 75005 Paris, France. Fax: 0033 (0)1 44273841 ; Tel: 00 33 (0)1 442755 62; E-mail: rodrigue.lescouezec@upmc.fr

b Instituto de Ciencia Molecular (ICMol), Facultat de Química, Universitat de València, C/ Catedrático José Beltrán 2, 46980 Paterna, València, Spain.

¥ This work was supported by the Ministère de l'Enseignement Supérieur et de la Recherche (MESR, France), the Erasmus Mundus program (lot 13), the Agence Nationale de la Recherche (Project: ANR-08-BLAN-0186-01) and the Ministerio Español de Ciencia e Innovación (Project CTQ 2010-15364) and generalitat Valenciana (PROMETEO/2009/108 and ISIC2012/002).

$\S$ best fit led to $\lambda_{\mathrm{Co}_{\mathrm{o}}}=-120 \mathrm{~cm}^{-1}, \mathrm{D}_{\mathrm{Co}_{\mathrm{o}}}=468 \mathrm{~cm}^{-1}, \alpha_{\mathrm{Co}_{\mathrm{o}}}=0.81, \lambda_{\mathrm{Fe}}=-372 \mathrm{~cm}^{-1}, \mathrm{D}_{\mathrm{Fe}}=-324 \mathrm{~cm}^{-1}, \alpha_{\mathrm{Fe}}=0.77$ and TIP $=0.025 \mathrm{~cm}^{3} \mathrm{~mol}^{-1} \mathrm{where}_{\mathrm{M}}$ $D_{M}, \alpha_{M}$ and TIP are the spin-orbit constant, the axial distortion, the orbital reduction factor and the temperature independent paramagnetism, respectively

\& Neglecting the spin-orbit interaction, the size of the Hamiltonian matrices to be considered are already equal to $67108864 \times 67108864$ By taking into accounts the spin-orbit coupling using the T-P isomorphism, ${ }^{27}$ the size becomes intractable with size larger than $32010^{12}$.

1 See themed issues on molecular magnets and molecule-based magnets: Dalton Trans., 2010, 39, 4653-5039 and Chem. Soc. Rev., 2011, 40, 30533368.

2 R. E. P. Winpenny, J. Chem. Soc., Dalton Trans. 2002, 1.

3 T. Lis, Acta Cryst. B, 1980, 36, 2042.

4 (a) A. Caneschi, D. Gatteschi, R. Sessoli, J. Am. Chem. Soc. 1991, 113, 5873; (b) R. Sessoli, D. Gatteschi, M. A. Novak, Nature, $1993,365,141$.

5 G. Aromi, E. K. Brechin, Struct. Bonding (Berlin Ger.) 2006, 122, 1.

6 M. Shatruck, C. Avendano, K. R. Dunbar, Prog. Inorg. Chem., 2009, 56, 155 and references herein.

7 (a) T. Mallah, S. Thiébaut, M. Verdaguer, P. Veillet, Science, 1999, 262, 1554; (b) O. Sato, T. Iyoda, A. Fujishima, K. Hashimoto Science, 1996,272, 704; (c) R. Lescouëzec, L. M. Toma, J. Vaissermann, M. Verdaguer, F. S. Delgado, C. Ruiz-Pérez, F. Lloret, M. Julve, Coord. Chem. Rev., 2005, 249, 2691; (d) D. Li, R. Clérac, S. Parkin, G. Wang, G. T. Yee, S. M. Holmes, Inorg. Chem. 2006, 45, 5251; (e) D. E. Freedman, D. M. Jenkins, A. T. Iavarone, J. R. Long, J. Am. Chem. Soc. 2008, 130, 2884; (f) K. S. Pedersen, M. Shau-Magnussen, J. Bendix, H. Weihe, A. V. Palii, S. I. Klokishner, S. Ostrovsky, O. S. Reu, H. Mutka, P. L. W. Tregenna-Piggott, Chem. Eur. J., 2010, 16, 13458.

8 G. Aromì, A. S. Batsanov, P. Christian, M. Helliwell, A. Parkin, S. Parsons, A. A. Smith, G. A. Timco, R. E. P. Winpenny, Chem. Eur. J. 2003,9 , 5142 .

9 A. B. Boeer, A.-L. Barra, L. F. Chibotaru, D. Collison, E. J. L. McInnes, R. A. Mole, G. G. Simeoni, G. A. Timco, L. Ungur, T. Unruh, R. E. P. Winpenny, Angew. Chem. Int. Ed. 2011, 50, 4007.

10 P. Albores, E. Rentschler, Angew. Chem., Int. Ed., 2009, 48, 9366.

11 F. Kloewer, F.; Lan, Y.; Nehrkorn, J.; Waldmann, O.; Anson C. E.; Powell, A. K. Chem. Eur. J., 2009, 15, 7413.

12 (a) M. Murrie, Chem. Soc. Rev., 2010, 39, 1986; (b) G. E. Kostakis, S. P. Perlepes, V. A. Blatov, D. M. Proserpio, A. K. Powell, Coord. Chem. Rev., $2012,256,1246$.

13 R. Lescouëzec, F. Lloret, M. Julve, J. Vaissermann, M. Verdaguer, Inorg. Chem., 2002, 41, 5943.

14 S. Wang, X.-H. Ding, J.-L. Zuo, X.-Z You, W. Huang, Coord. Chem. Rev., 2011, 255, 1713.

15 (a) R. Lescouëzec, J. Vaissermann, C. Ruiz-Pérez, F. Lloret, R. Carrasco, M. Julve, M. Verdaguer, Y. Dromzee, D. Gatteschi, W. Wernsdorfer, Angew. Chem., Int. Ed. 2003, 42, 1483; (b) L. M. Toma, R. Lescouëzec, J. Pasan, C. Ruiz-Pérez, J. Vaissermann, J. Cano, R. Carrasco, W. Wernsdorfer, F. Lloret, M. Julve, J. Am. Chem. Soc. 2006, 128, 4842; (c) H.-R. Wen, C.-F. Wang, Y. Song, S. Gao, J.-L. Zuo, X.-Z. You, Inorg. Chem., 2006, 45, 8942; (d) L. M. Toma, C. Ruiz-Pérez, F. Lloret, M. Julve, Inorg. Chem. 2012, 51, 1216

16 (a) D. Li, S. Parkin, G. Wang, G.-T Yee, R. Clérac, W. Wernsdorfer, S. M. Holmes, J. Am. Chem. Soc. 2006, 128, 4214; (b) D. F. Li, R. Clérac, O. Roubeau, E. Harté, C. Mathonière, R. L. Bris, S. M. Holmes, J. Am. Chem. Soc. 2008, 130, 252; (c) M. Nihei, M. Ui, N. Hoshino, H. Oshio, Inorg. Chem., 2008, 476106.

17 (a) T. Liu, Y.-J. Zhang, S. Kanegawa, O. Sato, J. Am. Chem. Soc. 2010, 132, 8250; (b) D.-P. Dong, T. Liu, S. Kanegawa, O. Sato, S. Kang, C. He, C.Y. Duan, Angew. Chem. Int. Ed. 2012, 124, 5209; (c) M. Nihei, Y. Okamoto, Y. Sekine, N. Hoshino, T. Shiga, I.-P. Liu, H. Oshio, Angew. Chem. Int. $E d ., 2012, \mathbf{5 1}, 6361$.

18 (a) S. Wang, J.-L. Zuo, H.-C. Zhou, H. J. Choi, Y. Ke, J. R. Long, X.-Z. You, Angew. Chem. Int. Ed. 2004, 43, 5940; (b) L. Jiang, H. J. Choi, X.-L. Feng, T.-B. Lu, J. R. Long, Inorg. Chem. 2007, 46, 2181.

19 B. N. Figgis, J. Lewis, F. E. Mabbs, G. A. Webb, J. Chem. Soc. A 1966, 422.

20 (a) F. Lloret, M. Julve, J. Cano, R. Ruiz-Garcia, E. Pardo, Inorg. Chim. Acta, 2008, 361, 3432; (b) see SI. 


\section{Supplementary information}

\section{Cyanide- and hydroxo-bridged nanocage: a new generation of magnetic coordination clusters.}

Abhishake Mondal, ${ }^{\dagger}$ Sonja Durdevik, ${ }^{\dagger}$ Lise-Marie Chamoreau, ${ }^{\dagger}$ Yves Journaux $^{\dagger}$ Miguel Julve, $§$ Laurent Lisnard, ${ }^{*} \dagger$, Rodrigue Lescouëzec*,

†Institut Parisien de Chimie Moléculaire (IPCM), UMR7201, UPMC Paris 6, 4 place Jussieu, 75252 Paris cedex5 (France); ${ }^{5}$ Instituto de Ciencia Molecular (ICMol), Facultat de Química, Universitat de València, Catedrático José Beltrán 2, 46980 Paterna, València (Spain). 
Synthesis of 1.

Crystal structure: data collection and refinement.

Table 1: Structural description of the $\mathrm{Co} 3$ clusters.

Table 2: BVS calculations.

Table 3: $\mathrm{Fe}-\mathrm{C}$ and $\mathrm{Fe}-\mathrm{N}$ bond length distances in $\AA$.

Figure S1a: representation of the $\left\{\mathrm{CO}_{3} \mathrm{~m}_{3}-\mathrm{OH}\right\}$ clusters with atom labels and BVS calculations for the oxygen atoms assuming cobalt(II). Top: $\mathrm{Co}(1)$ to $\mathrm{Co}(3)$. Bottom: Co(4) to Co(6).

Figure S1b: representation of the $\left\{\mathrm{CO}_{3} \mathrm{~m}_{3}-\mathrm{OH}\right\}$ clusters with atom labels and BVS calculations for the oxygen atoms assuming cobalt(II). Top: Co(7) to Co(9). Bottom: $\mathrm{Co}(10)$ to $\mathrm{Co}(12)$.

Fit of the magnetic data: details and comments.

Figure S2: M vs. H/T plot for 1 . 


\section{Synthesis of 1 .}

$\left[\mathrm{PPh}_{4}\right]\left[\mathrm{Fe}{ }^{\prime \prime \prime}(\mathrm{Tp})(\mathrm{CN})_{3}\right] \cdot \mathrm{H}_{2} \mathrm{O}^{[18]}(70.3 \mathrm{mg}, 0.1 \mathrm{mmol})$ and $\left[\mathrm{Co}_{2}\left(\mathrm{H}_{2} \mathrm{O}\right)(\text { piv })_{4}(\mathrm{Hpiv})_{4}\right]^{[13]}$ (285 $\left.\mathrm{mg} 0.3 \mathrm{mmol}\right)$ were both dissolved in pure acetonitrile solution $(8 \mathrm{~mL})$. These two solutions were stirred and heated to about approx. $60^{\circ} \mathrm{C}$ for 1 hour, and the warm $\left[\mathrm{Fe}(\mathrm{Tp})(\mathrm{CN})_{3}\right]^{-}$solution was then added dropwise into the $\left[\mathrm{Co}_{2}\left(\mathrm{H}_{2} \mathrm{O}\right)(\mathrm{piv})_{4}(\mathrm{Hpiv})_{4}\right]$ solution. The resulting purple solution was heated to approx. $60^{\circ} \mathrm{C}$ during one hour and finally filtered. Evaporation of the filtrate under ambient condition afforded $\mathrm{X}$-ray suitable red prismatic crystals over 4 days. Yield: $0.314 \mathrm{~g}(65 \%)$. Elemental analysis calcd (\%) for $\mathrm{C}_{180} \mathrm{H}_{279} \mathrm{~B}_{4} \mathrm{Co}_{13} \mathrm{Fe}_{4} \mathrm{~N}_{52} \mathrm{O}_{45.5}$ : $\mathrm{C}, 43.83 ; \mathrm{H}, 5.70 ; \mathrm{N}, 14.76$; found: $\mathrm{C}, 43.76 ; \mathrm{H}, 5.65$; $\mathrm{N}, 14.60$; selected IR vibration peaks $\left(\mathrm{KBr} / \mathrm{cm}^{-1}, 300 \mathrm{~K}\right): v=2514(\mathrm{BH}), 2160,(\mathrm{CN}$ from Fe"'I-CN-Co"l), 2102, 2074 (CN from Fe"-CN-Co"), 1594, 1550 (CO).

\section{Crystal structure: data collection and refinement.}

Crystal data for $1\left(\mathrm{C}_{180} \mathrm{H}_{279} \mathrm{~B}_{4} \mathrm{Co}_{13} \mathrm{Fe}_{4} \mathrm{~N}_{52} \mathrm{O}_{45.5}\right)$ : red blocks, monoclinic, space group $\mathrm{Cc}_{\text {, }} \mathrm{a}=20.6791(7)$, $\mathrm{b}=$

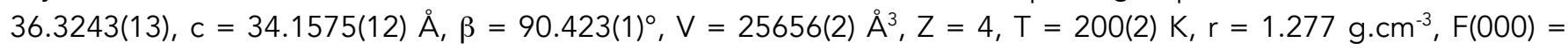
$10248, \mathrm{~m}(\mathrm{MoKa})=1.105 \mathrm{~mm}^{-1}$. Data were collected on a Bruker Kappa APEX-II CCD diffractometer (MoK $\alpha, \mathrm{I}=$ $0.71073 \AA$ A). Crystals were mounted on a Hamilton cryoloop using Paratone-N oil and placed in the cold flow produced with an Oxford Cryocooling device. Partial hemispheres of data -predefined with the APEX II software [BrukerAXS Inc, Madison, Wisconsin, USA, 1998] - were collected using and scans. Integrated intensities were obtained with SAINT [BrukerAXS Inc, Madison, Wisconsin, USA, 1998] and were corrected for absorption with SADABS [BrukerAXS Inc, Madison, Wisconsin, USA; Blessing, R. H. Acta Cryst. 1995, A51, 33]; The structure was solved by direct methods with SIR-92 [A. Altomare, G. Cascarano, C. Giacovazzo, A. Guagliardi, M. C. Burla, G. Polidori, M. Camalli J. Appl. Cryst. 1994, 27, 435.] and full-matrix least-squares refinement against $F^{2}$ was performed with the SHELXL [Sheldrick, G. M. Acta Cryst. 2008 A64, 112] to give, using 2576 parameters and 3 restraints, $w R_{2}=0.1346$ (55987 unique reflections), $R_{1}=0.0453$ (48048 reflections with $I>2 s(I)$ ), GOF $=1.034$, Flack parameter $=-0.019(7)$. There is a quite large void $\left(400 \AA^{3}\right)$ in the crystal structure, as underlined by Checkcif. There is residual density in this region and there must be missing solvent molecules in the proposed model. However, the low intensity of the residual peaks $\left(<1\right.$ e. $\left.\AA^{-3}\right)$ prevented any sensible refinement. Moreover, the most important residues are located around the pivalates of the Co1-Co2-Co3 triangle, showing that the disorder of this part is not fully modelled. As mentioned above, no sensible model could be obtained. Some tertio-butyl moieties of pivalates are disordered over two positions and refined isotropically. CCDC 890505 contains the supplementary crystallographic data for this paper. These data can be obtained free of charge via www.ccdc.cam.ac.uk/conts/retrieving.html (or from the Cambridge Crystallographic Data Centre, 12, Union Road, Cambridge CB2 1EZ, UK; fax: (+44) 1223-336-033; or deposit@ccdc.cam.ac.uk). 
Table 1: Structural description of the $\mathrm{Co} 3$ clusters.

$\left.\left[\mathrm{Co}_{3}(\mathrm{OH})(\text { piv) })_{4}(\mathrm{Hpiv})\right]_{2}\right]^{+}$
$[\mathrm{Co}(1), \mathrm{Co}(2), \mathrm{Co}(3)\}_{3}$
4 bridging pivalates, $\mu: \eta^{1}: \eta^{1}$.
2 terminal pivalic acids.
2 octahedral cobalt ions.
1 tetrahedral cobalt ion.


Table 2: BVS calculations ${ }^{1}$

\begin{tabular}{|c|c|c|}
\hline \multicolumn{2}{|c|}{ BVS calculated for Co(II) } & BVS calculated for Co(III) \\
\hline $\mathrm{Co}(1)$ & 1,9971 & 2,1326 \\
\hline $\mathrm{Co}(2)$ & 1,8311 & 1,9892 \\
\hline $\mathrm{Co}(3)$ & 2,0189 & 2,1489 \\
\hline $\mathrm{Co}(4)$ & 1,8964 & 2,0516 \\
\hline $\mathrm{Co}(5)$ & 1,9375 & 2,0636 \\
\hline $\mathrm{Co}(6)$ & 1,8984 & 2,0476 \\
\hline $\mathrm{Co}(7)$ & 1,8724 & 2,0160 \\
\hline $\operatorname{Co}(8)$ & 1,9340 & 2,1344 \\
\hline $\operatorname{Co}(9)$ & 1,9113 & 2,0620 \\
\hline $\operatorname{Co}(10)$ & 1,8940 & 2,0491 \\
\hline $\operatorname{Co}(11)$ & 1,9492 & 2,0796 \\
\hline $\operatorname{Co}(12)$ & 1,9029 & 2,0411 \\
\hline $\operatorname{Co}(13)$ & 1,8578 & 2,4344 \\
\hline
\end{tabular}

${ }^{1}$ a) I. D. Brown, D. Altermatt, Acta Crystallogr. 1985, B41, 244, b) N. E. Brese, M. O'Keeffe, Acta Crystallogr. 1991, B47, 192, c) M. O'Keeffe, N. E. Brese, Acta Crystallogr. 1992, B48, 152.

Table 3: $\mathrm{Fe}-\mathrm{C}$ and $\mathrm{Fe}-\mathrm{N}$ bond length distances in $\AA$.

\begin{tabular}{|c|c|c|c|c|c|}
\hline \multicolumn{6}{|c|}{$\mathrm{Fe}(\mathrm{III})$} \\
\hline \multirow[t]{6}{*}{$\mathrm{Fe}(1)$} & C3 & $1.9256(40)$ & \multirow[t]{6}{*}{$\mathrm{Fe}(3)$} & $\mathrm{C} 8$ & $1.9147(37)$ \\
\hline & C2 & $1.9270(41)$ & & C9 & $1.9236(39)$ \\
\hline & C1 & $1.9369(44)$ & & $\mathrm{C7}$ & $1.9299(37)$ \\
\hline & N105 & $1.9644(35)$ & & N304 & $1.9712(38)$ \\
\hline & N101 & $1.9661(41)$ & & N302 & $1.9752(35)$ \\
\hline & N103 & $1.9775(40)$ & & N300 & $1.9832(34)$ \\
\hline \multicolumn{6}{|l|}{$\mathrm{Fe}(\mathrm{II})$} \\
\hline \multirow[t]{6}{*}{$\mathrm{Fe}(2)$} & C4 & $1.8918(37)$ & \multirow[t]{6}{*}{$\mathrm{Fe}(4)$} & C10 & $1.8850(36)$ \\
\hline & $\mathrm{C} 6$ & $1.8923(37)$ & & C11 & $1.8861(38)$ \\
\hline & C5 & $1.8942(38)$ & & $\mathrm{C} 12$ & $1.8945(38)$ \\
\hline & N203 & $2.0023(35)$ & & N403 & $2.0102(36)$ \\
\hline & N205 & $2.0100(34)$ & & N401 & $2.0119(36)$ \\
\hline & N201 & $2.0175(34)$ & & N405 & $2.0152(35)$ \\
\hline
\end{tabular}



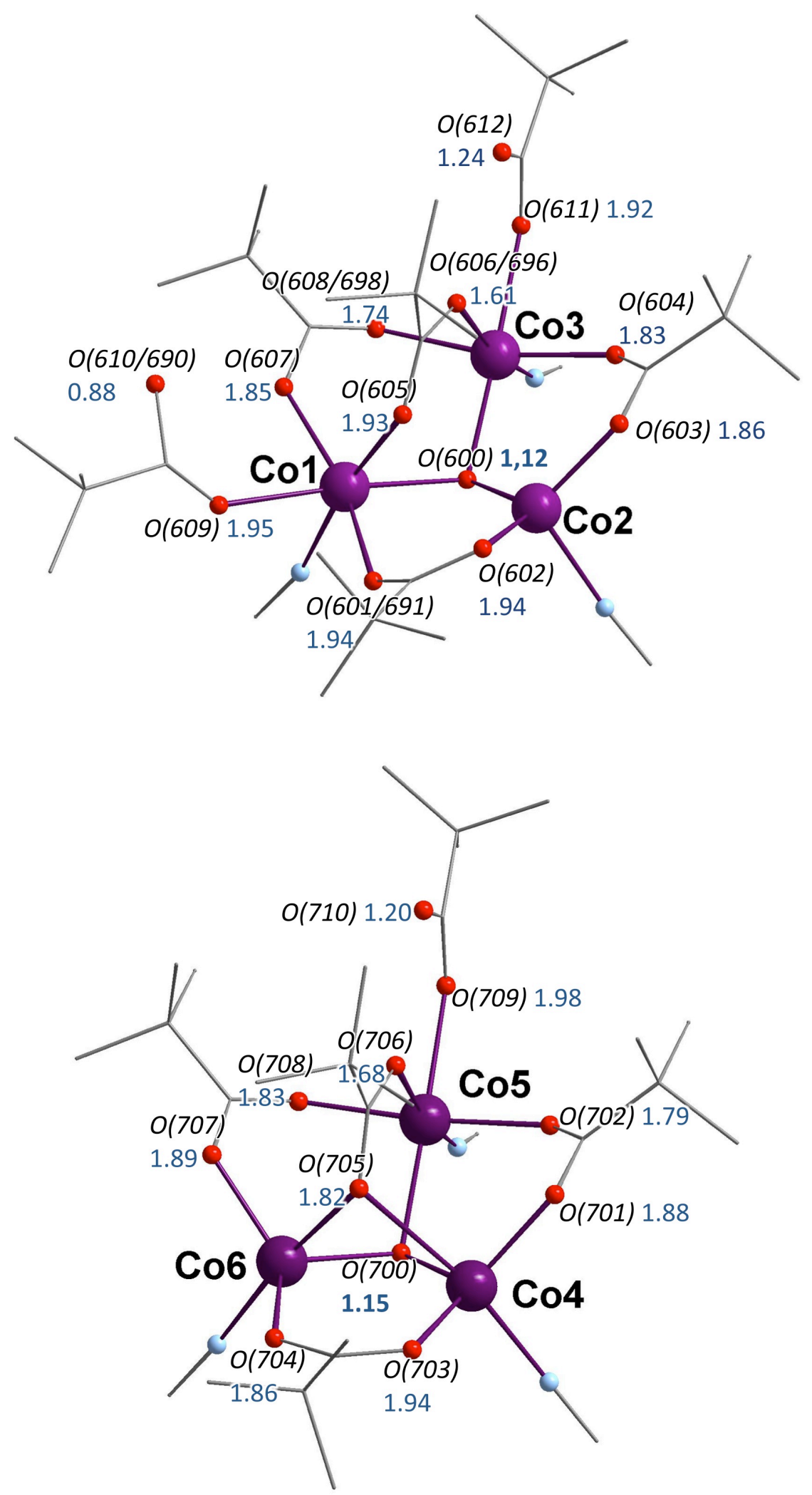

Figure S1a: representation of the $\left\{\mathrm{C}_{3} \mathrm{~m}_{3}-\mathrm{OH}\right\}$ clusters with atom labels and BVS calculations for the oxygen atoms assuming cobalt(II). Top: $\mathrm{Co}(1)$ to $\mathrm{Co}(3)$. Bottom: $\mathrm{Co}(4)$ to $\mathrm{Co}(6)$. 

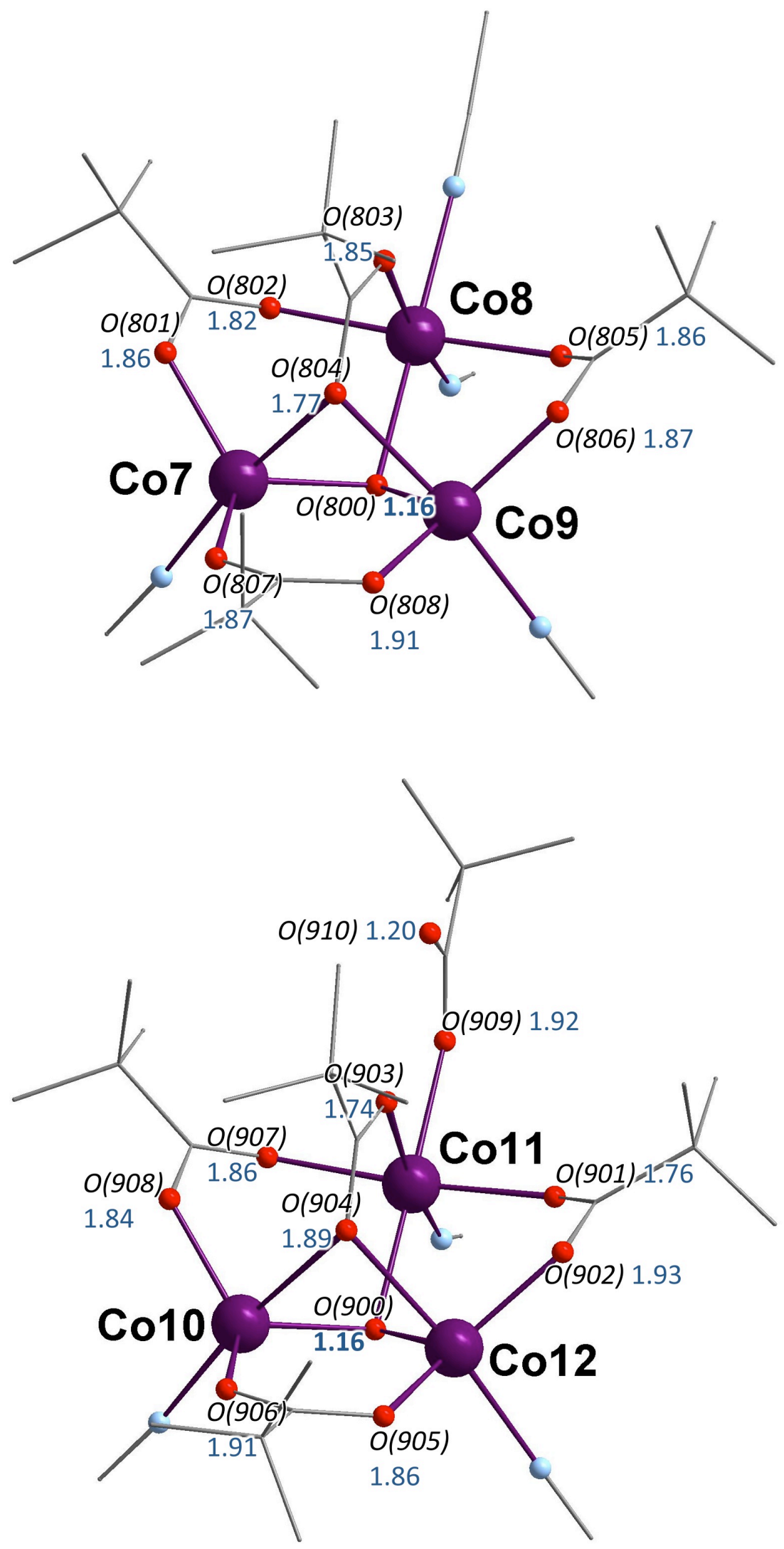

Figure $\mathrm{S} 1 \mathrm{~b}$ : representation of the $\left\{\mathrm{CO}_{3} \mathrm{~m}_{3}-\mathrm{OH}\right\}$ clusters with atom labels and BVS calculations for the oxygen atoms assuming cobalt(II). Top: $\mathrm{Co}(7)$ to $\mathrm{Co}(9)$.

Bottom: $\mathrm{Co}(10)$ to $\mathrm{Co}(12)$. 


\section{Fit of the magnetic data: details and comments.}

The system being composed of weakly coupled high-spin cobalt(II) ions and low-spin iron(III) ions, the magnetic data was modelled in the 300-50 K temperature range using the following Hamiltonian where the interaction between the magnetic ions are neglected [eq (1-3)]:

$H=\sum_{i=1}^{13} H_{i C o}+\sum_{j=1}^{2} H_{j F e}$

with

$H_{i M}=n a_{M} I_{M} L \cdot S+D_{M}\left[L_{z}^{2}-2 / 3\right]+b H\left[n a_{M} L+g_{e} S\right]$

The first term in the Hamiltonian (2) corresponds to the spin-orbit coupling effects, where $I_{M}$ with $M=C o, F e$ is the spin-orbit coupling constant and $\mathrm{a}_{\mathrm{M}}$ being the orbital reduction factor due to the existence of covalent character of bonds involving metal and ligands. The second term in this Hamiltonian accounts for the axial distortion of the six-coordinated Coll or Fe"ll ions. The last term represents the Zeeman interaction. The numerical coefficient $n$ depends on electronic configuration and comes from the isomorphic transformation which convert the hamiltonian for a ${ }^{2 S+1} T_{2}$ or ${ }^{2 S+1} T_{1}$ state into an hamiltonian for a ${ }^{2 S+1} \mathrm{P}$ term $(L=1)$. For high-spin cobalt(II) and low-spin iron(III) these coefficients are equal to $n=-3 / 2$ and $n=-1$ respectively. [1]

Adding a TIP term to take into account the effect of unpopulated exicted states, the least-squares fit of the experimental data of 1 using full diagonalisation of the Hamiltonian matrix performed in the $300-50 \mathrm{~K}$ temperature range led to $I_{\mathrm{Co}_{0}}=-120 \mathrm{~cm}^{-1}, D_{\mathrm{Co}_{0}}=468 \mathrm{~cm}^{-1}, \mathrm{a}_{\mathrm{C}_{0}}=0.81, \mathrm{I}_{\mathrm{Fe}}=-372 \mathrm{~cm}^{-1}, \mathrm{D}_{\mathrm{Fe}}=-324 \mathrm{~cm}^{-1}, \mathrm{a}_{\mathrm{Fe}}=0.77$ and $\mathrm{TIP}=0.025 \mathrm{~cm}^{3} \mathrm{~mol}^{-1}$. These values are in the expected range for high-spin cobalt(II) and low-spin iron(III) ions.

[1]R. M. Golding, Applied wave mechanics Van Nostrand Co, London, 1969 p 243.

\section{Reduced magnetisation plot $\mathrm{M}(\mathrm{H} / \mathrm{T})$}

The saturation magnetization value of $23.2 \mathrm{BM}$ for 1 (figure S2) is close to the calculated one (25 BM) with the best parameters obtained by the fit of c.T vs. T plot in the high temperature range. These reduce magnetisation $\mathrm{M}$ versus $\mathrm{H} / \mathrm{T}$ curves are recorded in the $1.8 \mathrm{~K}-8 \mathrm{~K}$ temperature range where it is impossible to neglect the interaction between the magnetic ions as shown by the c.T versus T plot. Given the size of the cluster (see ref 28), it is impossible to model these curves. However, the absence of a unique curve for the reduce variable $\mathrm{H} / \mathrm{T}$ can have two origins. Firstly, the anisotropy of the iron and cobalt ions results in nonsuperposable isofield curve. Secondly, the exchange interactions through the cyanide and through the oxo bridges are quite weak (as observed in numerous previously reported Fe-CN-Co based systems, and, in agreement with the treatment of the c.T vs. T plot). Thus numerous close-lying excited states lie close to the ground state, so that even at low temperature, the magnetization value results from a thermal distribution of various states. This distribution of close-lying levels also leads to nonsuperposable isofield curves. 


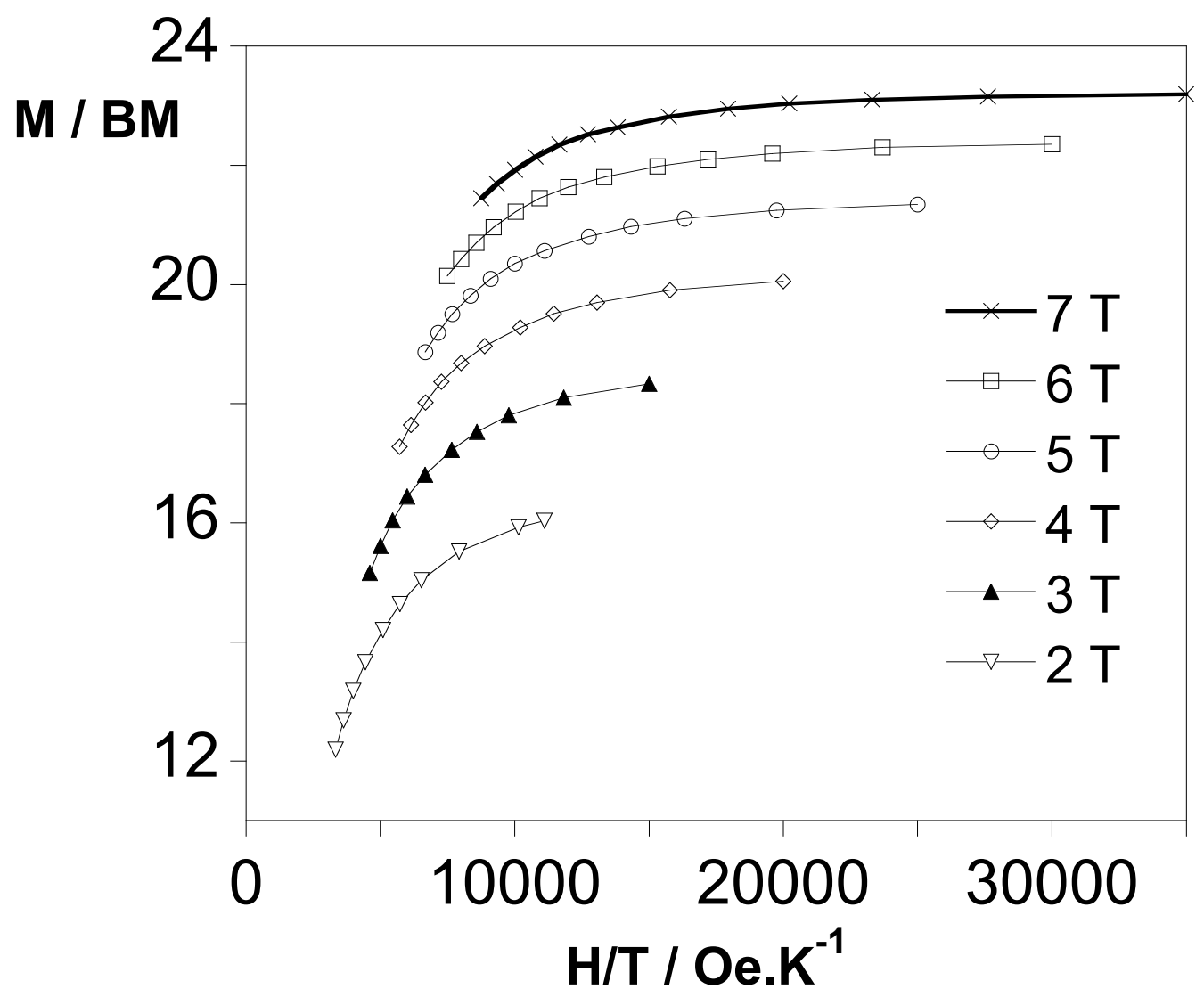

Figure S2: $M$ vs. H/T plot for 1 (solid lines are eye guides). 